\title{
Pós-graduação e produção científica: a teoria do capital humano e as demandas do setor produtivo
}

Ivson Conceição Silva

Pesquisador do LEPEL/FACED/UFBA

Leidiane Alves de Farias

Mestre em Estudos Interdisciplinares sobre Mulher, Gênero e Feminismo

Willian Santos

Pesquisador do LEPEL/FACED/UFBA

\section{Resumo}

O artigo apresenta como objetivo discutir os nexos e as contradições da conjuntura de surgimento e consolidação da pós-graduação brasileira e como a teoria do capital humano apresenta implicações na produção do conhecimento. Para tal, faz uma breve análise da conjuntura de seu surgimento e desenvolvimento, demonstrando as disputas por diferentes setores da burguesia dominante. Aponta como foi estabelecida uma aliança tácita entre a burguesia nacional e o capital internacional para contenção dos ideais marxistas nas universidades, fazendo prevalecer na produção do conhecimento as teorias do capital.

Palavras-chave: Pós-graduação; Produção do conhecimento; Conjuntura; Teoria do capital humano.

\section{Abstract}

The article presents as objective to discuss the connections and contradictions of the emergence of climate and consolidation of Brazilian graduate and how thPesquisador do LEPEL/FACED/UFBAe theory of human capital has implications for knowledge production. To this end, a brief analysis of the context of its emergence and development, demonstrating disputes by different sections of the ruling bourgeoisie. Points as a tacit alliance between the national bourgeoisie was established and international capital to contain the Marxist ideals in universities, making prevail in the production of knowledge the capital theories.

Keywords: Graduate; Production of knowledge; Conjuncture; The human capital theory.

Filosofia e Educação [RFE] - volume 8, número 3 - Campinas, SP

Outubro de 2016-Janeiro de 2017 - ISSN 1984-9605 - p. 142-168 


\section{Introdução}

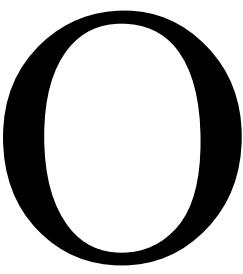

presente texto tem como objetivo discutir os nexos e as contradições conjunturais do desenvolvimento da pósgraduação no Brasil, a predominância da teoria do capital humano enquanto matriz epistemológica hegemônica e os setores capitalistas interessados na produção científica e seus desdobramentos na Educação Física.

Para tal discussão partimos de uma investigação bibliográfica identificando os nexos e contradições do modo de produção capitalista e as orientações de seus organismos nas pesquisas da pós-graduação brasileira. Nesse sentido questionamos: sob que conjuntura a pós-graduação se desenvolveu? Quais pressupostos teóricos balizaram a hegemonia na pósgraduação brasileira? Quais os segmentos interessados na pesquisa científica?

Os estudos sobre a produção científica no âmbito da Educação Física desenvolvidos por Silva (1997), Chaves (2005), Ávila (2008), Sá (2009; 2013), dentre outros, apontam a predominância de teorias que não buscam explicar seus objetos de pesquisa nas contradições do modo de produção capitalista. Dessa forma, a hegemonia do positivismo, da fenomenologia, do antirrealismo científico, da lógica formal para o desenvolvimento do pensamento, é expressão da luta de classes que se apresenta teoricamente na direção social que apontam a produção científica.

\section{Pós-graduação e a teoria do capital humano}

Desenvolvida tardiamente, se comparada aos sistemas de pós-graduação de outros países da América Latina e do mundo, resquício do próprio processo atrasado de implementação de uma universidade, a pós-graduação brasileira

\begin{tabular}{l}
\hline \hline Filosofia e Educação [RFE] - volume 8, número 3 - Campinas, SP \\
Outubro de 2016-Janeiro de 2017 - ISSN 1984-9605 - p. 142-168
\end{tabular}


teve seu reconhecimento em 1965 a partir do parecer 977, aprovado pelo conselho de educação, definindo o modelo organizacional da pós-graduação em mestrado e doutorado (MORALES, 2002)

Todavia, Cury (2005) destaca que, antes da regulamentação do sistema nacional de pós-graduação, inciativas isoladas de mestrados e doutorados já vinham ocorrendo em algumas universidades: UFMG e USP com doutorado em Direito, respectivamente em 1930 e 1941 e a PUC, com o mestrado em Sociologia. Ademais, a partir da década de 1950 as pesquisas científicas ganharam um novo impulso com a constituição de institutos de pesquisas ligados as cátedras, desenvolvendo assim, um papel importante das atividades de pesquisa no âmbito das universidades (COELHO; HAYASHI, 2011, p. 206).

Numa conjuntura de preconização de desenvolvimento nacional voltado para dentro, as autoridades nacionais já reconheciam a necessidade de promoção da pesquisa científica para elevar as condições do país na disputa do mercado mundial. Duas medidas foram importantes em 1950: a criação do Conselho Nacional de Pesquisa (CNP), atualmente Conselho Nacional de Desenvolvimento Científico e Tecnológico (CNPq), pela Lei ${ }^{\circ}$ 1.310/51 e, a Campanha de Aperfeiçoamento do Pessoal de Nível Superior (CAPES) - atual Coordenação de Aperfeiçoamento do Pessoal de Nível Superior -, pelo decreto $\mathrm{n}^{\mathrm{o}}$ 29.741/51 (SAVIANI, 2005; CURY, 2005; COELHO; HAYASHI, 2011) com a finalidade de apoiar a pesquisa científica e a qualificação profisssional mediante financiamentos dos institutos para promoção de cursos de especialização, dando origem aos centros de excelência.

De acordo com Leher e Motta (2014), esse período configurou-se um vigoroso momento de busca do "domínio das tecnologias nucleares e 
aeroespaciais; dos processos de extração de petróleo; da agronomia e das ciências afins; com a genética; da geologia entre outras coisas" (LEHER; MOTTA, 2014, p. 64).

Nessa direção, o $\mathrm{CNPq}$ estabeleceu como um dos objetivos o desenvolvimento de pesquisas na área nuclear, todavia, foi embargado pelos EUA, haja vista a necessidade de manter o papel do Brasil, na divisão internacional do trabalho, de fornecedor de matéria-prima, minérios estratégicos. Esse embargo impossibilitou a criação de uma indústria nuclear, reorientando as atividades da pós-graduação brasileira para as áreas das ciências exatas e biológicas (CUNHA, 1983, p. 156-158).

Anísio Teixeira, na condição secretário geral da comissão instituída em 1951 para promover a Campanha Nacional de Aperfeiçoamento de pessoal de nível superior, ${ }^{1}$ estimulou a cooperação entre professores e instituições estrangeiras, concedendo bolsas de estudos e incentivos para eventos científicos nacionais e internacionais. Segundo Cury (2005), o acordo foi firmado com

[...] os Estados Unidos pelo qual se celebraram diversos convênios entre universidades. Assim, muitos estudantes foram para os Estados Unidos a fim de fazer mestrado ou doutorado. E muitos professores norte-americanos vieram para o Brasil para desenvolver programas de pósgraduação" (CURY, 2005, p. 9).

Teixeira, na crítica à escola nova, defendia que escola era uma reprodução da sociedade na qual estava inserida, e por isso deviria acompanhar seu desenvolvimento material com a finalidade de preparar o

1 Anísio Teixeira foi o principal tradutor das obras de Dewey no Brasil.

Filosofia e Educação [RFE] - volume 8, número 3 - Campinas, SP

Outubro de 2016-Janeiro de 2017 - ISSN 1984-9605 - p. 142-168 
indivíduo para adaptar-se as mutabilidades societárias. (SAVIANI, 2005). A pós-graduação como uma fase da educação escolarizada deveria estar articulada com as modificações da sociedade moderna.

Dado que a natureza da civilização moderna se define pelo conhecimento lastreado na experimentação tendo, pois, a ciência como base do progresso, sua primeira grande tendência é a mentalidade de mudança contínua que se expressa numa "atitude de segurança, de otimismo e de coragem diante da vida" (Teixeira, 1968, apud SAVIANI, 2005, p. 10).

A referência pedagógica é o fazer científico em prol do desenvolvimento. Germina uma tendência tecnicista de fundamento produtivista que ganhou vulto na ditadura-empresarial-militar.

Essa tendência se manifestou explicitamente nas leis $(5.540 / 68)$ da reforma do ensino superior educacional e na LDB $(5.692 / 71)$ que teve com princípio norteador a racionalidade, a produtividade, não duplicação dos meios para os mesmos fins e maximização dos resultados com o mínimo de gastos (SAVIANI, 2005).

Nesse viés, a educação se torna um elemento fundamental para o desenvolvimento econômico, logo um bem produtivo. Essa orientação político-pedagógica é uma das facetas da teoria do capital humano como nova matriz hegemônica da educação e da gênese da pós-graduação brasileira.

A teoria do capital humano como ideologia desenvolvimentista, representa, dentre outras, na fase monopolista do capitalismo, uma apologia em que o oligopólio é a expressão da nova forma societária. No que diz 
respeito à educação e aos processos pedagógicos "[...] vai ligar-se à toda a perspectiva tecnicista que se encontra em pleno desenvolvimento na década de1950. Neste aspecto há um duplo reforço" (FRIGOTTO, 2006).

Para não apresentar explicitamente sua função econômica-políticaideológica no âmbito educacional e pedagógico, a teoria do capital humano, oculta, sob a forma de produção técnica-científica dois aspectos:

[...] vai reforçar toda a perspectiva da necessidade de redimir o sistema educacional de sua "ineficiência" e, por sua vez, a perspectiva tecnicista oferece a metodologia ou a tecnologia adequada para constituir o processo educacional como um investimento - a educação geradora de um novo tipo de capital - o "capital humano". A educação, para essa visão, se reduz a um fator de produção (FRIGOTTO, 2006, p. 123).

Seu desenvolvimento, já nos anos 1954 por Skiner, enquanto resposta à necessidade das demandas dos processos de automação e mecanização é resultado das mutações ocorridas no mundo do trabalho. Seu surgimento com função política, econômica e ideológica se deu, na disputa ideológica pelo rumo da pós-graduação, numa conjuntura de tensão mundial gerada pela guerra fria e consequentemente da disputa de projetos societários, socialismo e capitalismo (FRIGOTTO, 2006). Sob essa tensão a pós-graduação ganhou lastro para seu desenvolvimento.

A teoria do capital humano, como pressuposto epistemológico da pós-graduação, se apresenta pela relação que estabelece entre a educação, a produção da ciência para atender ao mercado, pela iniciativa do Estado e das instâncias de planejamento na direção do pleno emprego (SAVIANI, 2005).

Filosofia e Educação [RFE] - volume 8, número 3 - Campinas, SP

Outubro de 2016-Janeiro de 2017 - ISSN 1984-9605 - p. 142-168 
Apresenta-se com finalidade, não da educação em sentido ontológico, mas, na perspectiva da formação como instrumento de produtividade, que não possibilita ao ser humano conhecer e explicar cientificamente todo o processo da produção.

Na análise de Saviani (2005) essa concepção legou para a educação, o que o autor denomina de tendência produtivista. E afirma que

[...] procedeu-se ao ajuste do sistema de ensino à nova situação decorrente do golpe militar de 1964. Isto foi feito por meio da lei 5.540/68 e do decreto 464/69 no que se refere à reforma do ensino superior e pela lei 5.692/71 no tocante aos ensinos primário e médio que passaram a ser denominados de $1^{\circ}$ e $2^{\circ}$ graus. Em termos teóricos buscou se imprimir uma nova orientação pedagógica inspirada na "teoria do capital humano" (SAVIANI, 2005, p. 19).

Segundo Kuenzer e Morales (2005) foi, sobretudo, a partir dos anos de 1970, sob o autoritarismo do governo militar, através de uma aliança tácita com as elites acadêmicas e intelectuais que tinham em comum o nacionalismo e a convicção na ciência e tecnologia, que a pós-graduação se consolidou e se expandiu com objetivo de atender as demandas industriais do chamado "milagre econômico".

Com a crise europeia do padrão fordista/taylorista nos anos de 1970, a ruptura com o modelo keynesiano, o desemprego estrutural e o processo de produção flexível (HARVEY, 1992), a ciência e a tecnologia tornaram-se cada vez mais predominantes nos processos produtivos dos países de capitalismo avançado, tornando-se urgente a alteração político-econômica 
dos países em desenvolvimento sob o tema de ajuste e desenvolvimento para que pudessem captar e receber recursos para pagamentos de suas dívidas.

Para Chesnais (1996, p. 56) o que de fato acontece a partir dos anos 1970 é a concretização da etapa de mundialização do capital que se caracteriza sobre três pilares substanciais: intercâmbio comercial, investimento produtivo no interior e o fluxo de capital financeiro/monetário. Nesse sentido o capital externo influiu, mas precisamente em espaços com ampla capacidade de absorção de produção excedente de extração de maisvalia, seja pela exploração direta da força de trabalho ou pela subversão da subjetividade humana. Nesse sentido, a pressão interna exercida pelos setores pró-imperialistas da burguesia nacional - financeiro, de agronegócio e de commodities (LEHER, 2007) -, e as pressões externas exercidas pelos organismos multilaterais tiveram suas bases na teoria do capital humano como norteadora de suas ações.

Nesse contexto, há no âmbito da educação a necessidade de alteração substantiva para conformação às novas condições objetivas impostas pelo capital. A teoria do capital humano continua vigorando, mas assumindo uma nova aparência. Segundo Gentili (2002),

Passou-se de uma lógica da integração em função de necessidades e demandas de caráter coletivo (a economia nacional, a competitividade das empresas, a riqueza social etc.) para uma lógica econômica estritamente privada e guiada pela ênfase nas capacidades e competências que cada pessoa deve adquirir no mercado educacional para atingir uma melhor posição no mercado de trabalho (GENTILI, 2002, p. 51).

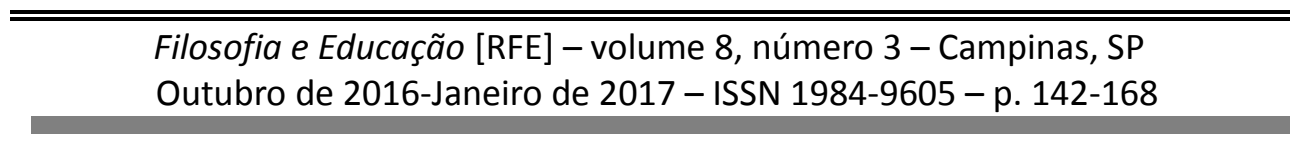


Com o desemprego estrutural (ANTUNES, 2009), a educação para ser reponsabilidade do indivíduo em buscar suas competências e habilidades (FACCI, 2009) para conquistar os empregos que estão disponíveis no mercado. Assim, quanto maior o grau de escolaridade, mais alta é a possibilidade de ter condições para a empregabilidade.

Nessa conjuntura que se deu o processo de regulamentação da pósgraduação, enquanto novo nível de ensino, instituído pelo presidente Castelo Branco, através do Parecer 977, de $1965^{2}$, elaborado por Newton Sucupira, que tratou da origem histórica, da necessidade e do conceito da pósgraduação, bem como das diretrizes para sua implementação. Em 1965, contabilizava-se 27 cursos de mestrados e 11 de doutorado, totalizando 38 no Brasil. Todavia, dirigido ao Conselho Federal de Educação, o parecer teve sua regulamentação definitiva apenas em 1969 com a implementação do parecer $n^{\circ}$ 77/69 (SAVIANI, 2005, p. 26-27) - conhecido como parecer Sucupira.

O modelo de pós-graduação adotado pelo Brasil apresenta duas influências: na sua estrutura organizacional está baseada no sistema educacional norte-americano, adotando os fundamentos da Escola Nova, que secundariza na educação básica o domínio dos conteúdos, tendo seu revés no ensino superior. Já seu desdobramento prático fundamenta-se no modelo Europeu ocidental de educação básica, que prima por um grau de autonomia intelectual dos ingressantes, dado o domínio dos conteúdos na educação básica (SAVIANI, 2010).

2 Disponível em: https://www.capes.gov.br/images/stories/download/legislacao/Parecer_CESU_977_1965.pd f. Acesso em 13.07.2015.

Filosofia e Educação [RFE] - volume 8, número 3 - Campinas, SP

Outubro de 2016-Janeiro de 2017 - ISSN 1984-9605 - p. 142-168 
Coelho e Hayashi (2011), ao se deterem no estudo da institucionalização da pós-graduação no Brasil, apontam como esta foi erigida num período caracterizado pelas reformas educacionais influenciadas pela pedagogia tecnicista, sendo a educação um pressuposto de desenvolvimento econômico atrelado aos interesses de mercado preconizado pela teoria do capital humano, mediante um projeto políticoeconômico

Fundamentado no binômio segurança e desenvolvimento, que projetava o crescimento econômico do Brasil visando completar o processo de industrialização do país, sempre subordinado aos interesses do capitalismo internacional, mas dentro de um regime de ordem social, conquistada com repressão social [...] (COELHO; HAYASHI, 2011, p. 194).

Instituindo paulatinamente a regulamentação da pós-graduação, a partir do modelo norte-americano e definindo novas diretrizes para educação superior, a trajetória teórica do sistema de pós-graduação empreende-se sob o julgo de um Estado centralizador, autoritário, destruidor e silenciador dos movimentos de luta populares, bem como numa conjuntura de antagonismo de projetos societários entre socialismo e capitalismo.

Uns dos elementos cruciais para apontar a predominâncias das teorias do capital na produção do conhecimento em Educação Física foi o processo coercitivo do governo empresarial-militar sobre a forma de pensar e produzir ciência, principalmente sobre os professores universitários que apresentavam histórico de militância contra o regimento social vigente. $\mathrm{O}$ patrulhamento ideológico, principalmente da teoria marxista, foi uma marca 
desse período, sendo criadas inclusive as Assessorias Especiais de Segurança e Informações - AESI -, cujo objetivo foi vigiar o conhecimento que estava sendo produzido e disseminado nas universidades (LEHER e MOTTA, 2014).

A ofensiva do Estado tirano, contra autonomia e liberdade universitária, rebateu diretamente na produção do conhecimento procedente da pós-graduação, uma vez que trataram de expropriar autores ${ }^{3}$ que foram considerados irrelevantes para os problemas da ciência e que poderiam gerar “mal estar" junto aos financiadores das pesquisas (LEHER; MOTTA, 2014).

Essa vigilância refletiu numa ciência preconizada pelo Estado que interessava ao capitalismo monopolista, passou a ser balizada pelas diretrizes das agências de fomento atreladas aos organismos multilaterais. Dessa forma, a pós-graduação se robusteceu com as políticas modernizantes e orientação teórica hegemônica a favor do capital que repercutiu na ciência brasileira, conforme destacam Leher e Motta (2014):

[...] É preciso lembrar que em 1965 existiam 36 programas, em 1976 já podiam ser contados 669 programas, crescimento que seguiu vertiginoso até o final da ditadura, em 1985, quando foram computados 1.116 cursos. A institucionalização da pesquisa, o estreitamento dos programas com os grupos de pesquisa que contaram com o apoio da ditadura e a participação de muitos dos docentes que eram líderes de grupos e de programas de pós-graduação nos conselhos dos órgãos de fomento à C\&T, contraditoriamente, possibilitaram ainda maior

3 Segundo Leher e Motta (2014), autores como Florestan Fernandes, Rui Mauro Marini, Vânia Bambirra, Theotônio dos Santos, Miriam Limoeiro Cardoso, eram considerados "malditos".

Filosofia e Educação [RFE] - volume 8, número 3 - Campinas, SP

Outubro de 2016-Janeiro de 2017 - ISSN 1984-9605 - p. 142-168 
controle do Estado sobre as pesquisas (LEHER; MOTTA, 2014, p. 66).

Mesmo com a produção científica hegemônica da pós-graduação comprometida com os interesses dominantes, haja vista a aliança entre elite acadêmica de direita e os militares, isso não significou parcimônia do polo contraditório. A militância de esquerda mesmo com suas forças minadas, falta de investimento, não publicação de suas produções em revistas financiadas a favor da ordem, espaço de trabalho precário, excesso de trabalho etc., resistiram e conseguiram formar importantes quadros de professores pesquisadores comprometidos com os interesses da classe trabalhadora, que continuam o enfretamento de classe, mesmo nas condições desfavoráveis, produzindo conhecimento com base teórica sólida e socialmente referenciada.

Contudo, a pós-graduação se forja com objetivo de formar uma elite pensante noutro grau acadêmico num período de massificação do ensino superior (CUNHA, 1983) as pesquisas desenvolvidas preteriram abordar os problemas sócio-político-econômicos do modo de produção capitalista, deixando esse ponto fulcral para explicação da realidade como mero coadjuvante em que é possível conviver pacificamente com tudo e com todos e sempre que necessário a melhor saída é a reforma.

Esse caráter elitista da pós-graduação também foi constatado nas análises dos documentos oficiais da época realizado por Cunha (1974). Segundo o autor,

A função social da pós-graduação, na ótica proposta, é a de restabelecer o valor econômico e simbólico do diploma do ensino superior. Como o número de

\begin{tabular}{l}
\hline \hline Filosofia e Educação [RFE] - volume 8, número 3 - Campinas, SP \\
Outubro de 2016-Janeiro de 2017 - ISSN 1984-9605 - p. 142-168
\end{tabular}


graduados aumentou a um ritmo acelerado, o valor do diploma de graduação caiu: sua posse deixou de ser distintiva, não indica mais que o graduado é "naturalmente" adequado para as ocupações que exigem maior "qualificação" e "responsabilidade", e, em consequência, são mais bem remuneradoras (CUNHA, 1974, p. 68).

A proposição elitista da pós-graduação é clara, formar para distinguir os que pensam dos que executam. Saviani (2010), ao analisar as tendências pedagógicas produtivistas predominantes na pós-graduação, aponta como a teoria do capital humano é enfatizada como necessária para o desenvolvimento econômico e tecnológico do país. Originalmente, num contexto de bem estar social, entendendo a educação como preparação de pessoas educadas para atuar no mercado de trabalho rumo ao pleno emprego. Todavia, com a crise do capital nos anos 1970, a restauração produtiva com novos níveis tecnológicos e com o desemprego estrutural, a teoria do capital foi reconfigurada, passando a educação "[...] a ser entendida como um investimento em capital humano individual que habilita os indivíduos para a competição pelos empregos disponíveis" (SAVIANI, 2010, p. 37-40).

Dessa forma, a produção científica no âmbito da Educação Física e outras áreas do conhecimento, que se valem da teoria do capital humano preconizadas na pós-graduação, são também responsáveis por prolongar o tempo de vida do sociometabolismo do capital, fortalecendo assim, o capitalismo dependente no Brasil e produzindo, em nome da ciência, tautologias. 
Marx (2011), ao tecer a crítica aos economistas do século XVII, demonstra o quanto é falso abstrair das investigações os determinantes das condições materiais, no qual o objeto sofre múltiplas determinações. $\mathrm{O}$ autor aponta como os que explicam seus objetos descolados das condições materiais acabam por produzir ilusões sobre o real, pois, assim como fez Hegel, concebe a realidade como fruto do pensamento e não seu inverso.

Por essa razão, para a consciência para a qual o pensamento conceitualizante é o ser humano efetivo, e somente o mundo conceituado enquanto tal é mundo efetivo - a consciência filosófica é assim determinada os movimentos das categorias aparecem, por conseguinte como ato de produção efetivo - que infelizmente, recebe apenas um estímulo exterior -, cujo resultado é o mundo efetivo; e isso - que, no entanto é uma tautologia- é correto na medida em que a totalidade concreta como totalidade do pensamento é de fato um produto do pensar, do conceituar; mas de forma alguma é produto do conceito que pensa fora e acima da intuição e da representação, e gera a si próprio, sendo antes produto da elaboração da intuição e da representação em conceitos. O todo como todo de pensamento, tal como aparece na cabeça, é um produto da cabeça pensante que se apropria do mundo único modo que lhe é possível, um modo que é diferente de sua apropriação artística, religiosa e praticomental. O sujeito real, como antes, continuar a existir em sua autonomia fora da cabeça; isso é claro enquanto a cabeça se comportar apenas de forma especulativa, apenas teoricamente. Por isso também no método teórico 
o sujeito, a sociedade, tem de estar continuamente presente como pressuposto da representação (MARX, 2011, p. 55).

Como afirma Marx (2011), a consciência filosófica é forjada pelo grau de imersão do pesquisador na realidade concreta para captar o real concreto no pensamento, caso contrário, ocorrem teorizações vazias, pois os conceitos vêm de dentro para fora, justamente porque não conhece a realidade.

Nesse contexto, a produção do conhecimento gerada na pósgraduação brasileira com base nas teorias hegemônicas, vem produzindo ilusões sobre a realidade, a partir de suas investigações que falseiam as contradições do modo de produção capitalista para manutenção de seu projeto societário. Isso acontece devido à predominância hegemônica das teorias do capital, que negam o mundo real e as teorias do conhecimento que apanham as contradições da sociedade de classe, dando assim, prosseguimento ao projeto implantado pela aliança entre os militares e a burguesia nacional, orientada pelos Estados Unidos via organismos multilaterais.

\section{Setores interessados na produção da pós-graduação}

A necessidade de continuar a superprodução de mercadorias e o esgotamento dos sistemas de organização do trabalho taylorista/fordista gerou um processo de transformações no modo de produção capitalista para o padrão de acumulação flexível (HARVEY, 1992). O Estado perdeu a sua capacidade de administrar o impulso da economia mundial e, passou a controlar os investimentos sociais, atacar os organismos da classe - 
sindicatos, centrais, associações etc. - a fim de garantir o "soberano" funcionamento do mercado numa fase de economia competitiva (REIS; RODRIGUES, 2006).

Nessa metamorfose do capitalismo mundial, a universidade sofreu as intervenções necessárias aos ajustes do capital e a produção científica. Em tempos de eficiência e eficácia passou a ser requisitada para o desenvolvimento dos processos produtivos.

Ademais, desde a reforma universitária de 1965-1968 os segmentos da burguesia nacional tiveram assentos nas comissões e conselhos para ditar qual o conhecimento e o profissional requerido na graduação e pósgraduação. De acordo com Reis e Rodrigues (2006) a Confederação Nacional da Indústria (CNI) com objetivo de formar mão-de-obra qualificada propuseram seis ações articuladas:

Em primeiro lugar, maior rigor na transferência de recursos para as universidades públicas, mediante a avaliação da qualidade. Em segundo lugar, identificação dos centros de excelência. Em terceiro lugar, criação de incentivos fiscais para promover a canalização de recursos privados para o sistema público de ensino, desde que garantida a participação direta das empresas na decisão sobre a destinação desses recursos. Em quarto lugar, implementação de programas especiais de alfabetização (português e aritmética) voltados para a força de trabalho industrial efetivamente empregada. Em quinto lugar, flexibilização no regime de dedicação exclusiva dos docentes-pesquisadores. Finalmente, a CNI propõe ações para uma maior integração entre as 
empresas e as universidades (ou centros de pesquisa) de forma a garantir benefícios para a indústria, através da criação, nos centros de pesquisa e nas universidades, de conselhos definidores de linhas estratégicas de pesquisa com a participação efetiva dos empresários. Os empresários também devem, na visão da entidade, participar dos órgãos governamentais responsáveis pela formulação da política tecnológica (REIS; RODRIGUES, 2006, p. 3).

Fica evidente que a burguesia industrial buscou valorizar a ciência e educação que atendesse diretamente seus interesses. Dessa forma, a produção científica da pós-graduação comprometida com o capital não tinha e não tem interesse em compreender e explicar os nexos e as contradições do financiamento privado de pesquisa em universidades públicas para apropriação privada do setor produtivo.

De acordo com Leher (2010) os programas de pesquisa passaram a ser induzidos pelos organismos internacionais, corporações monopolistas e governo com a finalidade de manter a ordem vigente. $\mathrm{O}$ autor sinaliza que

Merece destaque o papel das fundações particularistas estrangeiras (ligadas às corporações), que influenciaram a agenda e a forma de produzir conhecimento objetivando reduzir o espaço dos estudos marxistas. Essas fundações incidiram de modo deliberado para modificar a agenda da pesquisa social no Brasil e na América Latina. Criaram programas de bolsas e financiamento para determinadas agendas e grupo de pesquisa tinham abandonado a perspectiva, apoiando, ainda revista em que essa

\begin{tabular}{l}
\hline \hline Filosofia e Educação [RFE] - volume 8, número 3 - Campinas, SP \\
Outubro de 2016-Janeiro de 2017 - ISSN 1984-9605 - p. 142-168
\end{tabular}


produção "renovada" pudesse ser colocada em circulação (LEHER, 2010. p. 36).

Foi por essa linha coercitiva subjetiva e objetivamente de disputa da formação da classe trabalhadora, que durante e pós-ditadura os grupos de pesquisa nas universidades que se converteram - ou, que desde o princípio estiveram de acordo com os interesses privatistas do capital -, constituíram sua hegemonia teórica no âmbito da pós-graduação.

Dessa forma, a incessante busca para responder o problema da verdade, a partir da crítica radical ao sistema de exploração capitalista, ficou debilitada; e, a produção científica no âmbito da pós-graduação aprisionada aos dispositivos empregados pela hegemonia do capital.

Em tempos de políticas neoliberais orientadas pelos organismos multilaterais, a produção do conhecimento da pós-graduação tem sua agenda elaborada com objetivo de atender as demandas globais das políticas de Ciência, Tecnologia e Informação (CHUAÍ, 2003). Essa que deve ser seguida vis a vis sem questionamento pelos partidários do capitalismo, não pelos seus adversários de classe, que se valem dela para acirrar as contradições por dentro do jogo e promover sua superação.

Assim, no contexto do padrão de acumulação flexível (HARVEY, 1992), a pós-graduação e, consequentemente a produção do conhecimento hegemônica são configuradas para alimentar a irracional lógica da denominada sociedade do conhecimento $^{4}$, exigindo uma formação

4 Para Chauí (2003, p. 9), a noção de sociedade do conhecimento está longe de indicar uma possibilidade de grande avanço e desenvolvimento autônomo das universidades como instituições sociais comprometidas com a vida de suas sociedades e articuladas a poderes e direitos democráticos, considerando tanto a heteronomia universitária (quando a universidade produz conhecimentos destinados ao aumento de informações para o capital financeiro, submetendo-se às suas necessidades e à sua lógica) quanto a irrelevância da atividade universitária (quando suas pesquisas são autonomamente definidas ou quando

Filosofia e Educação [RFE] - volume 8, número 3 - Campinas, SP

Outubro de 2016-Janeiro de 2017 - ISSN 1984-9605 - p. 142-168 
tecnocrática, pragmática a-histórica e a-científica que resulte em quantidades de produtos, ainda que sem qualidade, mas que alimente o sistema de avaliação da CAPES e dos indicadores internacionais. Chaú (2003), ao desenvolver a crítica sob a perspectiva operacional que a universidade vem paulatinamente assumindo, nos sinaliza que esta vem sendo

[...] regida por contratos de gestão, avaliada por índices de produtividade, calculada para ser flexível, a universidade operacional está estruturada por estratégias e programas de eficácia organizacional e, portanto, pela particularidade e instabilidade dos meios e dos objetivos. Definida e estruturada por normas e padrões inteiramente alheios ao conhecimento e à formação intelectual, está pulverizada em microorganizações que ocupam seus docentes e curvam seus estudantes a exigências exteriores ao trabalho intelectual. A heteronomia da universidade autônoma é visível a olho nu: o aumento insano de horas/aula, a diminuição do tempo para mestrados e doutorados, a avaliação pela quantidade de publicações, publicações, colóquios e congressos, a multiplicação de comissões e relatórios etc. (CHAUÍ, 2003. p. 7).

Sobre o rebatimento dessa operacionalização da universidade na pesquisa científica, a autora aponta que 
[...] a pesquisa segue o padrão organizacional. Numa organização, uma "pesquisa" é uma estratégia de intervenção e de controle de meios ou instrumentos para a consecução de um objetivo delimitado. Em outras palavras, uma "pesquisa" é um surveyde problemas, dificuldades e obstáculos para a realização de um objetivo, e um cálculo de meios para soluções parciais e locais para problemas e obstáculos locais. O surveyrecorta a realidade de maneira a focalizar apenas o aspecto sobre o qual está destinada a intervenção imediata e eficaz. Em outras palavras, o surveyopera por fragmentação. Numa organização, portanto, pesquisa não é conhecimento de alguma coisa, mas posse de instrumentos para intervir e controlar alguma coisa. Por isso mesmo, numa organização não há tempo para reflexão, a crítica, o exame de conhecimentos instituídos, sua mudança ou sua superação. Numa organização, a atividade cognitiva não tem como nem por que se realizar (CHAUÍ, 2003. p. 7-8).

A pesquisa e organização preconizadas pelos organismos internacionais do capital no âmbito da pós-graduação buscam focalizar suas ações para resolução de problemas imediatos, cada vez mais específicos, fragmentando ainda mais a totalidade que o objeto se encontra. Isso implica na rápida obsolescência do conhecimento, uma vez que não busca alcançar medidas de longo alcance com base teórica consistente para chegar a raiz do problema, demandando uma nova explicação sobre algum fragmento não explicado, implicando assim no produtivismo acadêmico.

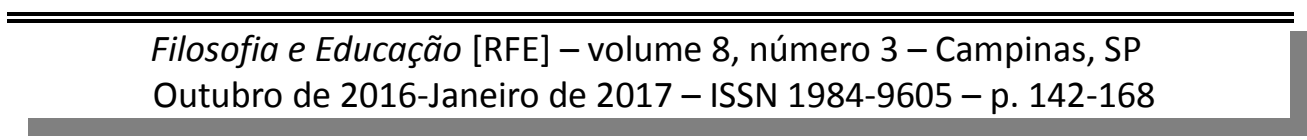


Os estudos desenvolvidos Silva Júnior e Sguissardi (2009, 2013) vêm demonstrando que esse produtivismo acadêmico - instituído pelo sistema de avaliação da CAPES e a indução das pesquisas aplicadas pelo $\mathrm{CNPq}$ e pelos organismos internacionais do capital - tem intensificado o trabalho docente e gerado um processo de desumanização e estranhamento nas relações do trabalho nas universidades públicas no âmbito da pósgraduação.

Sob o discurso da inovação, racionalidade, eficiência e eficácia novas exigências são postas para que o professor-pesquisador tenha suas pesquisas financiadas pelas agências de fomentos, conforme as orientações dos organismos multilaterais. Assim, atendendo as prioridades do mercado, da CAPES e CNPq, estabelece-se uma "nova cultura acadêmica" a favor do capital. Não obstante, desde 2001, o financiamento de pesquisa por demanda espontânea foi suprimida, passando a custear as pesquisas induzidas via edital, a partir de áreas consideradas estratégicas pelo setor produtivo e pelo capital financeiro para o desenvolvimento do país. Isto é,

$\mathrm{O}$ reordenamento e a reorganização da Capes e do $\mathrm{CNPq}$ permitiram que ambas as agências orientassem a pesquisa e a produção do conhecimento para a valorização do capital, priorizando projetos de inovação para o desenvolvimento de novas tecnologias que agregassem valor aos produtos e processos e beneficiassem desta maneira os interesses econômicos privados. Por outro, lado por meio de processo de certificação em massa, na educação superior, procura-se formar o novo trabalhador (SILVA JÚNIOR; SGUIRSSADI, 2013, p. 128). 
Nessa dimensão de valorização do capital a pós-graduação e a universidade pública entrega tudo que o setor privado deseja em troca de parcos financiamentos: produz o conhecimento para o setor capitalista; forma o trabalhador na universidade pública e a mão de obra qualificada para a docência na rede privada e para os setores produtivos; tem sua expansão contida, favorecendo a rede privada; compra produtos resultados de pesquisas desenvolvidas dentro da própria universidade pública etc.

Nesse sentido, a ação do governo brasileiro para eliminar as burocracias se expressa nas leis de inovação: 11.196/2005, que tem com objetivo promover mais incentivos fiscais às empresas privadas que desenvolvam atividades junto às universidades; 10.168/2000, cujo objetivo foi estimular o desenvolvimento tecnológico brasileiro, mediante programas de pesquisa científica e tecnológica na cooperação entre universidades, centros de pesquisa e o setor produtivo à inovação; 10.973/2004 que tem como objetivo estimular a pesquisa realizada em cooperação entre universidades e setor produtivo para desenvolvimento tecnológico autônomo do país.

Essa (des)regulação exigida pelo mercado não trata de aproximar a universidade pública da empresa privada, mas, de efetivamente converter um bem social, como a educação e a produção do conhecimento desenvolvida nestas universidades, em produto de mercado, como vem sendo orientado pela Organização Mundial do Comercio-OMC. Os estudos desenvolvidos porNeave (apud MAÚES, 2004), demonstram como o projeto que descola a universidade pública da demanda social vem se efetivando desde 1980 na América do Norte - Estados Unidos e Canadá - e na Europa Ocidental - França, Alemanha, Inglaterra e Países Baixos. Predominando nesses países a política de custo com especificidade à 
produção, assim como vem acontecendo no Brasil com as políticas mediadas pela CAPES e CNPq desde anos 2000.

Essas regulações mercadológicas no âmbito do principal centro de produção científica brasileira - a pós-graduação - têm levado as universidades públicas constantemente a uma intensificação pelo viés produtivista, racional, técnico-pragmático de Estado. Desse modo, com a adoção desses modelos importados há uma retração orçamentária e contraditoriamente um aumento de pressão para elevar a produção científica na pós-graduação, a fim de alcançar as metas dos indicadores avaliativos e entregar ao setor produtivo os conhecimentos requeridos para acumulação do capital.

\section{Considerações finais}

A pós-graduação brasileira foi regularmente reconhecida e implementada sob a doutrina do binômio segurança-desenvolvimento do governo empresarial-militar. É possível reconhecer que os interesses pela pesquisa neste nível de formação tiveram diretamente ligados a politica de continuidade do processo de industrialização atrasada do Brasil. Essa condição requisitou da universidade a formação de mão obra qualificada (graduação) e superqualificada (mestrado e doutorado), assim como, uma ciência comprometida com os interesses dos setores produtivos com base epistemológica na teoria do capital humano. Isso demandou em nome do nacionalismo e da ciência uma aliança tácita entre governo autoritário e a elite acadêmica da direita que tentou erradicar das universidades brasileiras a teoria marxista enquanto teoria do conhecimento que busca explicar os objetos estabelecendo os nexos e as contradições do modo de produção capitalista.

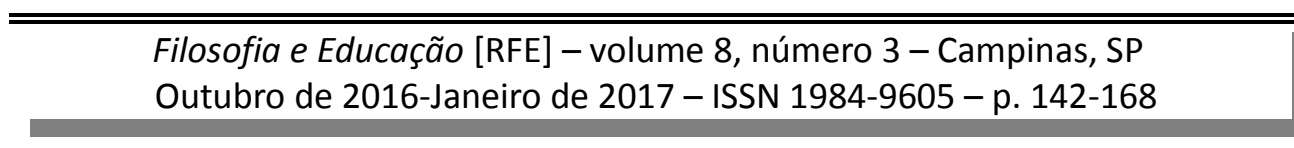


Essa coerção nos ajuda a compreender como se expressa na produção científica no âmbito da Educação Física a hegemonia das teorias que não buscam compreender e explicar seus objetos estabelecendo os nexos, as contradições e movimento com o modo de produção capitalista. Assim, o financiamento do setor privado nacional e internacional das multinacionais nas universidades públicas orientou através de seus representantes de classe, CNI, CAPES, CNPQ etc. quais os conhecimentos necessários deveriam ser produzidos para o desenvolvimento do setor produtivo e que tipo de trabalhador deveria ser formado preterindo a militância contra o governo autoritário, o projeto de formação da classe trabalhadora e o projeto histórico socialista.

Reconhecemos ainda, que na política neoliberal de maximização do capital, o Estado emprega cada vez menos recurso financeiro para produção da ciência, estrangulando as condições necessárias para o desenvolvimento da pesquisa obrigando ao professor-pesquisador a ter que buscar na iniciativa privada recursos financeiros (agora também empreendedor). Estabelece assim, uma relação explicitamente de compra e venda de conhecimento, a propósito, culmina na privatização do conhecimento gerado pela parceria público-privado.

Desse modo, apontamos que a produção do conhecimento hegemônica da pós-graduação brasileira é determinada por fatores externos, que buscam não suprir as carências humanas, mas as mercadológicas, além de coadunar com as contradições do modo de produção capitalista. Nessa condição, o professor-pesquisador no processo de subjetivação e objetivação produz algo que se torna estranho a ele, o produto de seu processo de produção não é para o seu desfrute, mas para outro, os financiadores das pesquisas.

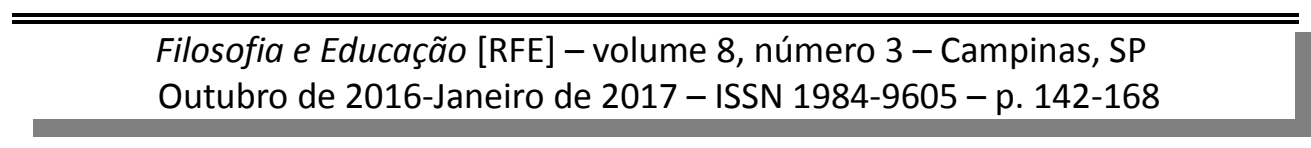


Para superar essa contradição é necessário que a produção científica da Educação Física gestada na pós-graduação seja socialmente referenciada, isto é, que busque atender as carências humanas imediatas, mediatas e históricas e tenha como horizonte a superação do modo de produção da vida que homens exploram outros homens, para um modo de produção de trabalhadores livres associados, o comunismo.

\section{Referências}

ÁVILA, A. B. A pós-graduação em educação física e as tendências na produção de conhecimento: o debate entre realismo e anti-realismo. 2008. 233 f. Tese (doutorado), Centro de Ciências da Educação. Universidade Federal de Santa Catarina, 2008.

CHAUÍ, M. A universidade pública sob nova perspectiva. Revista Brasileira de Educação [online], Rio de Janeiro, n. 24, p. 5-15, Set /Out /Nov/ de 2003.

CHESNAIS, F. Mundialização: o capital financeiro no camanando. Outubro, São Paulo, n. 5, 2001.

COELHO, M.; HAYASHI, M. C. Pós-graduação no regime militar. Série-Estudos: Periódico do Programa de Pós-Graduação em Educação da UCDB, Campo Grande-MS, n. 31, p. 193-213, jan./jun. 2011

CUNHA, L. A. A pós-graduação no Brasil: Função Técnica e Função Social. Revista de Adminstração de Empresa, São Paulo, v.14, n.5, p. 66-70. set./out.1974. - A universidade Crítica. Rio de Janeiro: Francisco Alves, 1983.

CURY, C. R. (2005). Quadragésimo ano do parecer CFE no 977/65. Revista Brasileira de Educação, Rio de Janeiro, n.30, p. 7-20, set/out/nov/dez de 2005.

Filosofia e Educação [RFE] - volume 8, número 3 - Campinas, SP Outubro de 2016-Janeiro de 2017 - ISSN 1984-9605 - p. 142-168 
- Uma lei de reforma universitária e seus itinerários. Revista HISTEDBR, Campinas (on-line)v. 9, n.35, p. 59-75. set. de 2009.

GENTILI, Pablo. Três teses sobre a relação trabalho e educação em tempos neoliberais. In: LOMBARDI, J. C.; SAVIANI, D.; SANFELICE, J. L. (Org.). Capitalismo, trabalho e educação. Campinas: Autores Associados/HISTEDBR, 2002. p. 45-59.

HARVEY, D. A condição Pós-moderna. São Paulo: Loyola, 1992.

KUENZER, A. Z.; MORAES, M. C.Temas e tramas da pós-graduação no Brasil. Educação \& Sociedade, Campinas, v. 26, n. 93, p. 1.341-1.362, set./dez. 2005.

LEHER, R.; MOTTA, V. C. (2014). Trabalbo Docente crítico como dimensão do projeto de universidade. Germinal: Marxismo e Educação em debate, Salvador, v. 6, n.1, p. 48-78, jun. de 2014.

LEHER, R. Uma Universidade com o campo das humanidades estilhaçado: cenário futuro da UFRJ? CFCH, Rio de Janeiro, v.1, n.1, p. 34-52, jun. de 2010.

- A problemática da universidade 25 anos após a crise da dívida. Universidade e Sociedade,v. XVI, n.39, 9-15, fev.de 2007.

MARX, K. A ideologia alemã. 3.ed. São Paulo: Boitempo, 2014.

MELO, A. S. A mundialização da educação: consolidação do projeto neoliberal na América Latina. Brasil e Venezuela. MACEIÓ: EDUFAL, 2004.

MORALES, M. C. Avaliação na pós-graduação brasileira: novos paradigmas, antigas controvésias. In: L. Bianchetti, \& A. M. Machado. A búsula do escrever. São Paulo; Florianópolis: Cortez: UFSC. 2002.

MUÉS, O. Reforma universitária on modernização mercadologia das universidades públicas. Universidade e sociedade, Brasília, v. XIV, n. 33, p. 22-32, jun. de 2004. OLIVEIRA, J. F. A política de ciência, tecnologia e inovação, a pós-graduação e a produção do conbecimento no Brasil. Inter-Ação,Goiânia, v. 38, n. 2, p. 323-338, mai/ago de 2013.

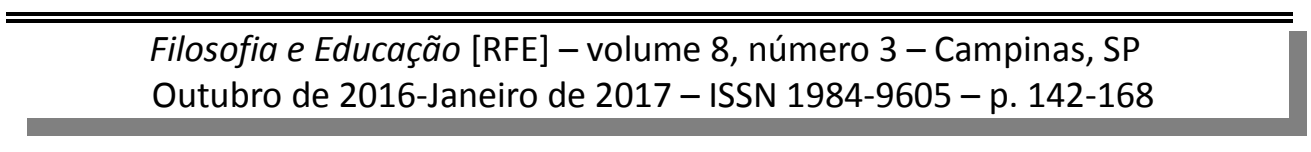


REIS, R; RODRIGUES, J. O declínio da universidade pública: considerações sobre o atual quadro das relações sociais de produção da educação superior pública brasileira. Cadernos Cemarx, Campinas, v. 1, n. 3, p. 183-194, 2006.

SÁ, K. O. Projetos integrados de pesquisa em rede: realidade e possibilidades da produção do conhecimento stricto sensu em educação física, esporte e lazer de professores que trabalham em cursos de formação de professores de educação física no estado da Bahia - 1982 a 2012. 2013.147 f. Relatório de (pósdoutoramento em Educação) Faculdade de Educação, Universidade Estadual de Campinas, 2013.

SAVIANI, D. Filosofia na formação do educador. In: Do senso comum à consciência filosófica. Campinas: Autores associados, 2009.

- O protagonismo do professor Joel Martins na pós-graduação. Revista Brasileira de Educação, Rio de Janeiro n. 30, p. 21-35,Dez 2005.

SILVA JUNIOR, J. D.; SGUIRSSADI, V. Universidade Pública Brasileira no Sáculo XXI Educaçâo superior orientada para o mercado e intensificaçâo do trabalho docente.Espac. blanco, Serie. indagaciones, v.23, n.1, p. 119-156, jun. de 2013.

SILVA JUNIOR, J. D. Pesquisa em Educação Física: determinações históricas e implicações epistemológicas. 1997. 278 f. Tese (Doutorado em Educação). Faculdade de Educação, UNICAMP, Campinas. 1997. 